\title{
Forest and Industrial Plantation Mapping with Multi- Temporal Dual Polarization by ALOS PALSAR Data In Riau Province
}

\author{
Elis Molidena a,c*, Takahiro Osawa b,c, Putu Gede Ardhana a, \\ Abd. Rahman As-syakur c \\ ${ }^{a}$ Graduate Study of Environmental Sciences, Udayana University, Denpasar, Bali 80232, Indonesia \\ ${ }^{b}$ Graduate School of Science and Engineering, Yamaguchi University, Ube Shi Tokiwadai 2-16-1, 7550092, Japan \\ c Center for Remote Sensing and Ocean Sciences (CReSOS), Udayana University, PB Sudirman Street, Denpasar, \\ Bali 80232, Indonesia \\ * Correspondence: molidena@yahoo.com
}

Received: 4 August 2017; Accepted: 31 May 2018; Available online: 1 June 2018

\begin{abstract}
Backscattering characteristics of land use has been analyzed using ALOS PALSAR data. The purpose of this research are mapping of land use by five categories such as forest, acacia, oil palm, open area and water, and to identify the changes of environmental. Analysis Pixel-by-pixel average of ALOS PALSAR level 1.5 backscattering used from five of category land use was to estimate the spectral characteristic of each object in difference $\mathrm{HH}$ and $\mathrm{HV}$ polarization. Ground truth data was taken from 169 locations which used for classification, 119 locations and 50 locations used for validation. Two different times of ALOS PALSAR level 1.02009 and 2010 data, was used for changes detection by multi temporal color composite combination. The accuracy result for classification map shows $62 \%$ of ground truth database, and multi temporal analysis showed the possibility of changes.
\end{abstract}

Keywords: ALOS PALSAR; land use; classification; change detection

\section{Introduction}

Rainforests cover takes only a small part of the earth surface, it's about $6 \%$ for total of the earth surface Forest is a natural resources that use for wildlife habitat, water quality protection and buffer to climate, but forest and land resources are important in social economic in developing countries like in Indonesia. Change of environmental quality that related with function changes, forest degradation and land use change, in developing country this issue become an attention. Sumatra lost 5,4 million hectares or 9,2\% of their forest cover between 2000-2008 (Butler, 2011), because of Riau Province has been under serious threat of rapids scale of deforestation (Uryu, et al., 2008), and have high land cover change especially in forest, forest cover in Riau decline by $65 \%$ over past 25 years (Uryu et al., 2008)

Remote sensing is an art and science to extract information about object, area or phenomena through data analysis that receive without direct contact with it (James B, 1987). There are two types of remote sensing system namely passive and active remote sensing. Passive remote sensing product is known as optic imagery. Active remote sensing Synthetic Aperture Radar (SAR), used for this research, SAR provides a promising alternative because it can penetrate clouds, as well as smoke and haze from fires. The Advance Land Observing Satellite (ALOS) carry an SAR sensor called Phased Array Lband Synthetic Aperture Radar (PALSAR). ALOS was launched by JAXA on 24 January 2006. The L-band SAR sensor penetrates the above ground biomass of tree trunks and canopies, independent of atmospheric conditions and observation time (day vs. night) 
(Roseqvist et al, 2007). The phase array type L-band Synthetic Aperture Radar (PALSAR) on board ALOS satellite provides higher performance. Although polarimetry is the state of art technology because of include the four type of polarization $\mathrm{HH}, \mathrm{HV}, \mathrm{VV}, \mathrm{VH}$. The imagery was well known with the polarimetric system that able to visual and digital identification, the conventional imaging mode of ALOS PALSAR is dual polarization mode to which $47 \%$ of the time resources are assigned compared to $7 \%$ for polarimetry (Feilong et al., 2008) and to take the advantages of dual polarization data of PALSAR for different application.

This research was made for mapping forest and industrial plantation in Riau Province. The objectiveness of this research are as follows;

- To mapping forest and industrial plantation with ALOS PALSAR dual polarization.

- To estimate the seasonal changes by the ALOS PALSAR backscattering.

\section{Materials and Methods}

\subsection{Research Study Area}

This research location is in boundary between Riau Province and Jambi Province. $100,94 \mathrm{E}$ to $101,74 \mathrm{E}$ and $0,48 \mathrm{~N}$ to $0,65 \mathrm{~S}$ (Figure 1). The north part of research location are Indragiri Hulu and Kuantan Sengingi district, the east and south part of this research is Jambi Province and in the west part is West Sumatra Province. Riau Province has three types of topographic elevation, first part is area with slope $0-2 \% 1.157 .006 \mathrm{Ha}$, second area with slope 15-40\% $737966 \mathrm{Ha}$ and third area with slope $>40 \% 550928 \mathrm{Ha}$ (Riau Government). Riau province has wet tropical climate with average of rainfall 1000-3000 $\mathrm{mm} /$ year affected by dry season and rainy season (BPS, 2010). This research was conducted over 9 month from October 2012 until July 2013.

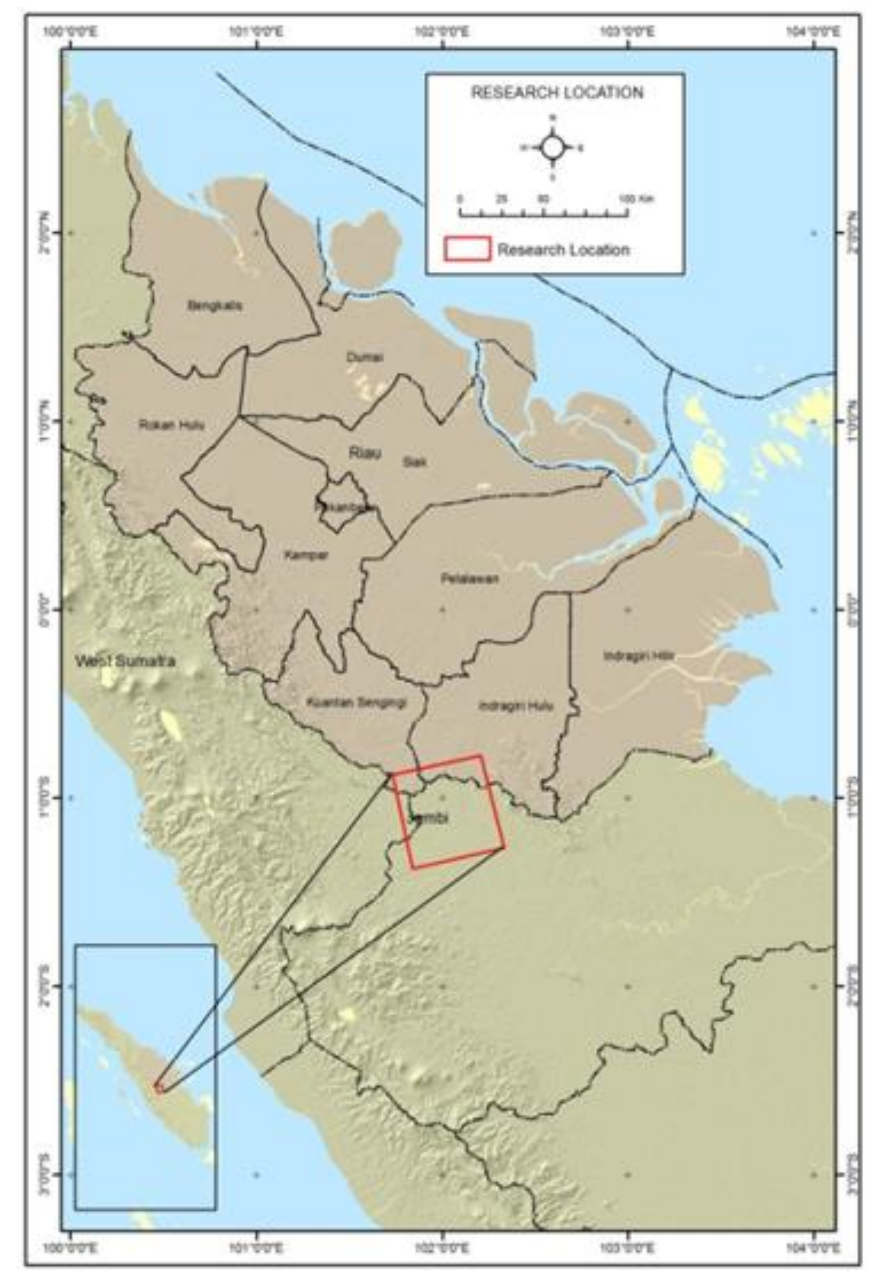

Figure 1. Research location 


\subsection{Data Collection}

Material of this research are ALOS PALSAR multi temporal dual polarization images, scene 4447180 level 1.0 two different acquisition dates (June 20 2009 and September $7^{\text {th }} 2010$ ) and 4447180 level 1.5 acquisition date June $23^{\text {th }}$ 2010. LANDSAT ETM+ image path 126 row 61 on June $18^{\text {th }} 2010$ and WWF ground truth data, with 169 locations of ground truth data (27 locations of forest, 33 locations of acasia, 27 locations of oil palm, 53 locations of open area, 29 locations of water.

\subsection{Data Analysis Method}

This study was devid by two parts, frist part is to conduct classification and second part is to detect seasonal changes from ALOS PALSAR L-band Image. PALSAR level 1.0 from different date were to detecte seasonal changes and PALSAR level 1.5 was converted to backscattering intensity value was used to the classification compare with and ground truth data. The acuracy test of these result is from ground truth data comparing with the image classification data. The framework of this research shows in figure 2.

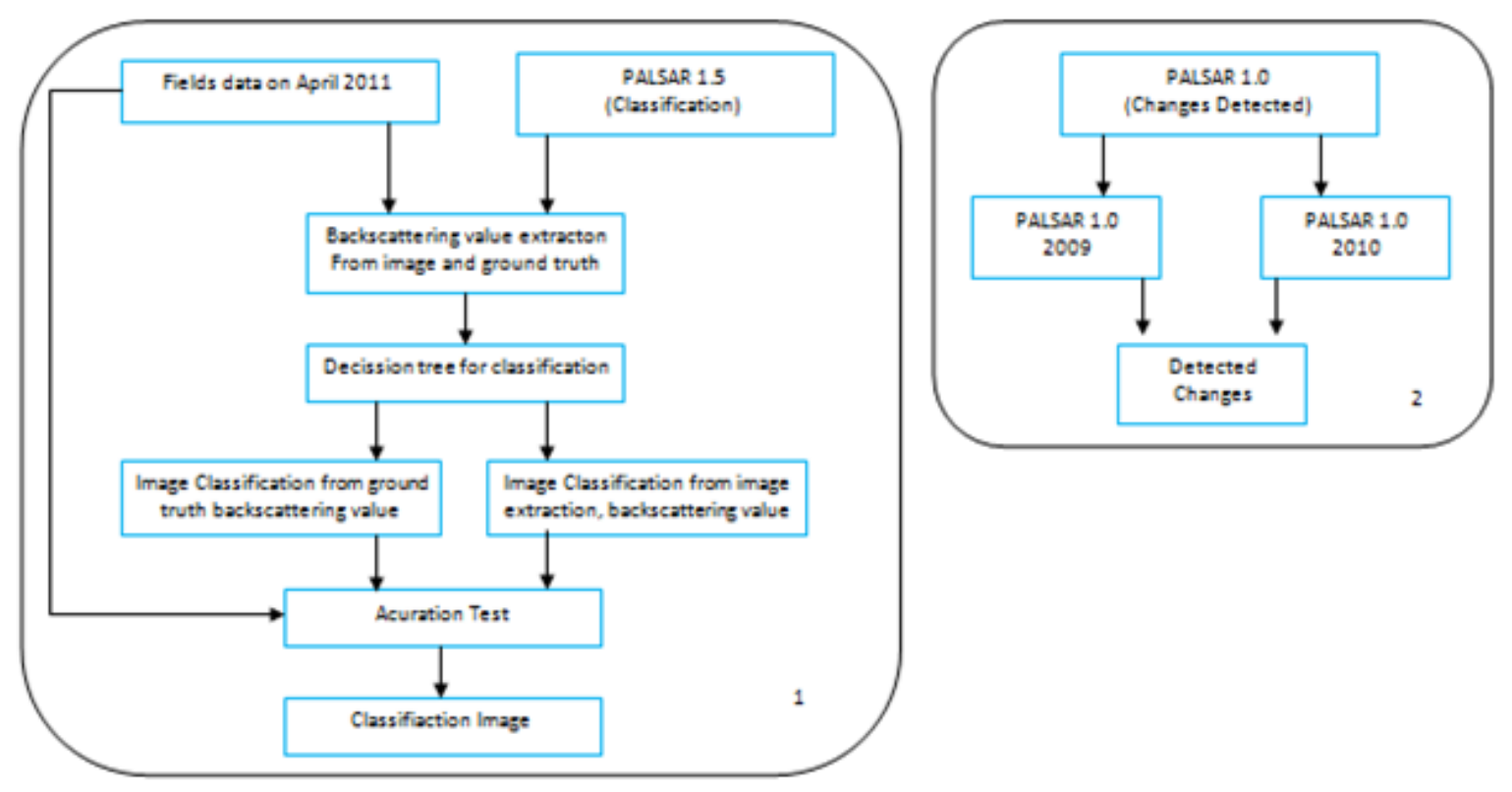

Figure 2. Research Framework

\subsubsection{Backscattering Analysis}

The backscattering coefficient was achieved by a normalization step where radiometric distortion due to the illumination areas was corrected using the local incidence angle. The intensity data in linear format can be transformed to dB format (Shimada et al., 2009).

$$
\begin{gathered}
\sigma^{o}=10 \times \log 10(D N)+C F \\
\sigma^{o}=\text { Backscatterintensity }(\mathrm{db})
\end{gathered}
$$

$\mathrm{DN}=$ Digital Number value of pixel in $\mathrm{HH}$ or HV

$\mathrm{CF}=$ Calibration Factor (-83 for Both $\mathrm{HH}$ and HV)

There are five-class category, such as forest, acasia, oil palm, open area and water. Ground check taken by WWF (World Wild Found) Indonesia, June 2010, with 169 point of location samples that represent that type of object such us forest, acacia, oil palm, open area, water, Figure 3 shows the distribution of ground truth point of location. 


\subsubsection{Multitemporal Analysis}

All digital change detection is affected by spatial, spectral, temporal, and thematic constraints. The type of method implemented can profoundly affect the qualitative and quantitative estimates of the disturbance (Colwell and Weber, 1981). Even in the same environment, different approaches may yield different change maps. This research based on per pixel classifiers and change information contain in backscattering of the image.

Color composite use as visual interpretation to detect changes, there are some types of color like primery colors, secondary colors. Primary colors are sets of colors that can be combined, the primary colors normally used are red, green, blue. The combination of any two primary colors creates a secondary color, Mixing of red and green light produces shades of yellow, mixing green and blue produces shades of cyan, and mixing red and blue produces shades of purple (Luckiesh, 1921; Figure 4).
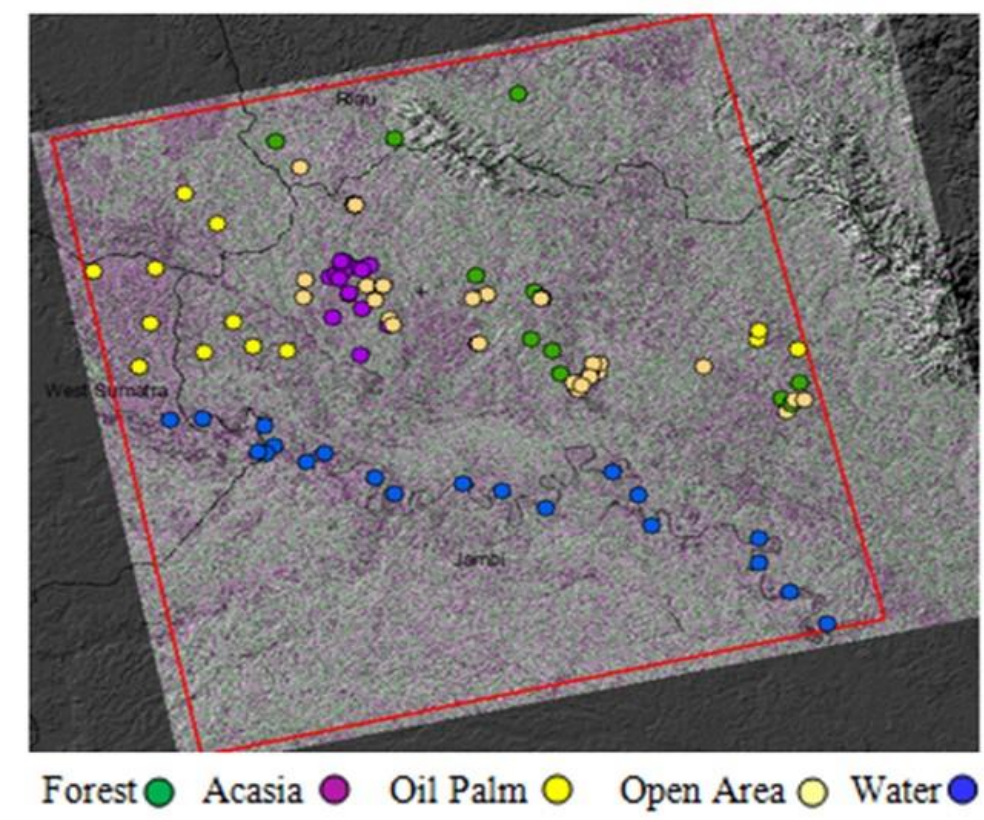

Figure 3. The distribution of gorund truth point of location

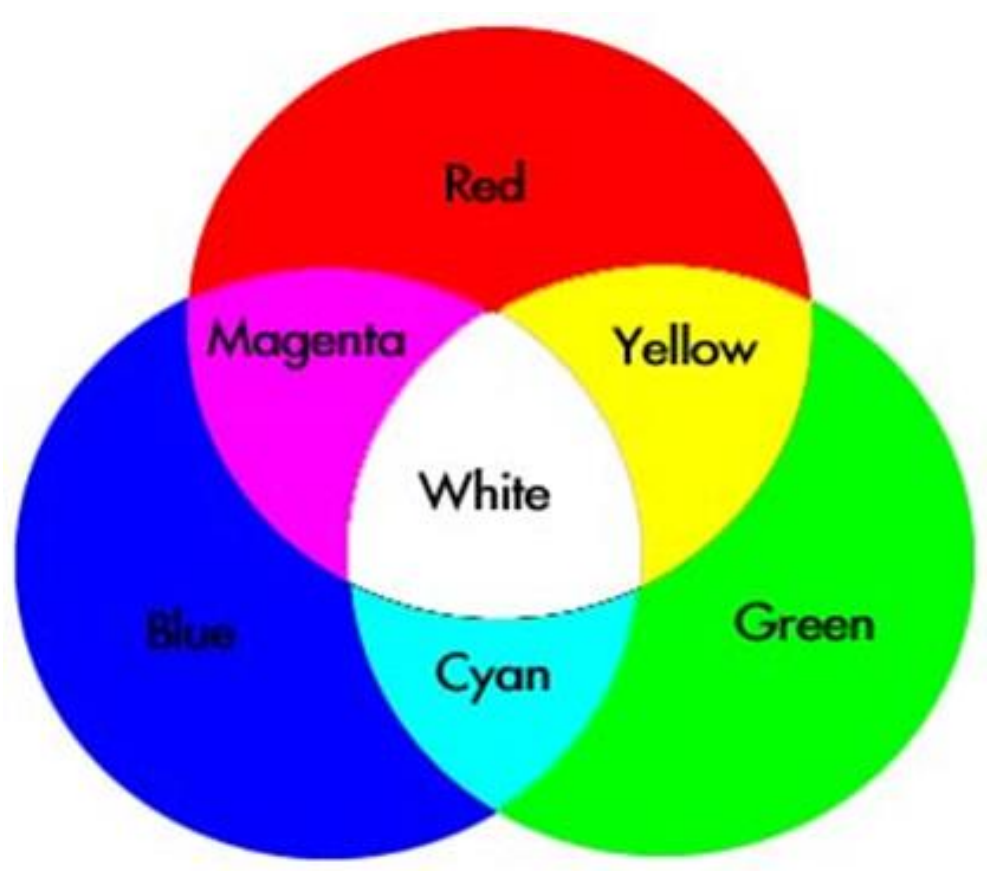

Figure 4. Primary colors and secondary colors 


\section{Results}

\subsection{Backscattering Intencity Analysis}

This research study is to divide five-land use type, such forest, acasia, oil palm, open area and water, by extract backscatter value based on backscatter intensity image from ground truth data as reference data for the land cover classification, and backscattering intensity from image as classification data. The signature of each land cover types from ground truth data were explored in HH, HV polarization, based on the graph water has the lowest backscatter intensity value $\mathrm{HH}$ and HV (Figure 5) than the other land cover types. Acacia and forest and oil palm has a similar backscattering value either in $\mathrm{HV}$ polarization and different value in $\mathrm{HH}$, forest has a highest backscattering value in $\mathrm{HH}$ and $\mathrm{HV}$, and acasia had the lower.

Backscattering value in vegetation types on both of $\mathrm{HH}$ and $\mathrm{HV}$ has the highest values. Furthermore, open area has mediate backscattering value on both $\mathrm{HH}$ and HV, while water has the lowest value on each $\mathrm{HH}$ and $\mathrm{HV}$ polarization. $\mathrm{HH}$ has highest value than $\mathrm{HV}$ on all five-class categories. Based on those values were defined procedures of decision tree to classify the data.

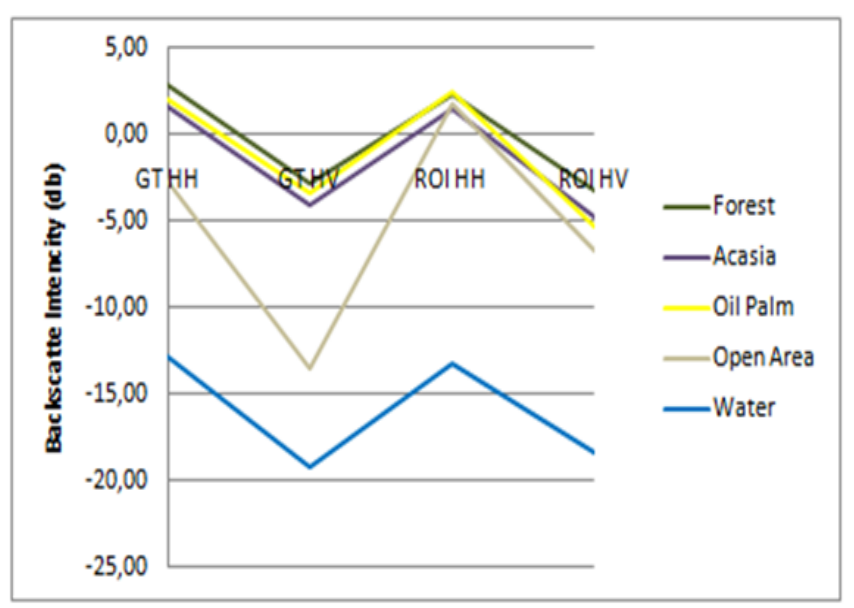

Figure 5. Relationship between Backscattering Intensity and Data

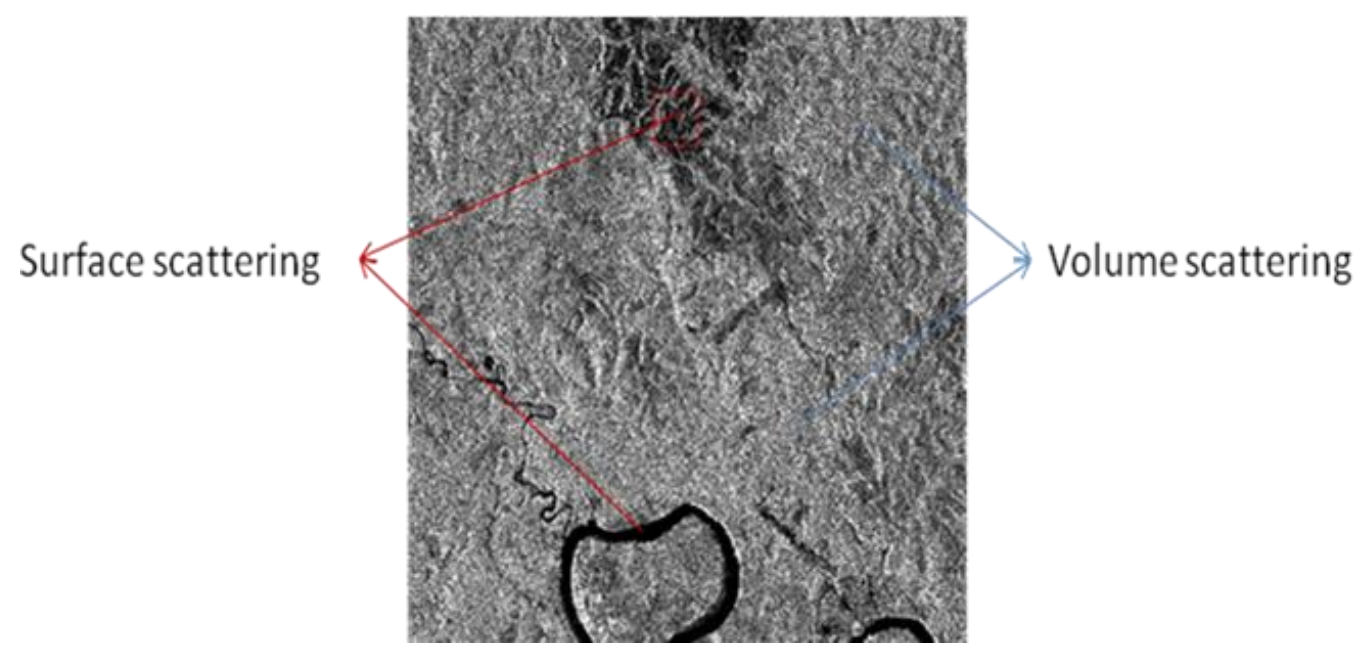

Figure 6. Surface scattering and volume scattering in image

\subsection{Scattering Mechanism}

Image extraction value of five category of land use defined by scattering mechanism. From this result, the volume scattering mostly occurred in forest area, or vegetation with 
high trees like acacia or mature oil palm. Surface scattering occurred in open area, young oil palm and water. Based on scattering mechanism and analysis backscattering, if we arrange the result value of backscattering intensity from the highest value to the lowest value we find that forest is the first highest value either in $\mathrm{HH}$ and $\mathrm{HV}$, acasia is the second of backscattering in HV but not in $\mathrm{HH}$, oil palm is the third value in HV but not in $\mathrm{HH}$. Open area is the forth value in HV but not in $\mathrm{HH}$ and water is the lowest value.

Classification test area carried out by comparison between PALSAR data with LANDSAT image. We define five land use category to utilize test area base on visual interpretation of Landsat imagery and compare with the PALSAR images, and then we extracted the backscattering information from PALSAR image. The result presented the acasia spread following the forest. Oil palm and open area has the similar backscattering intensity statistic value. Moreover, water has lowest value compared to the other object.

The classification image from ground truth data has $62 \%$ accuracy and the classification from image has $54 \%$ accuracy.
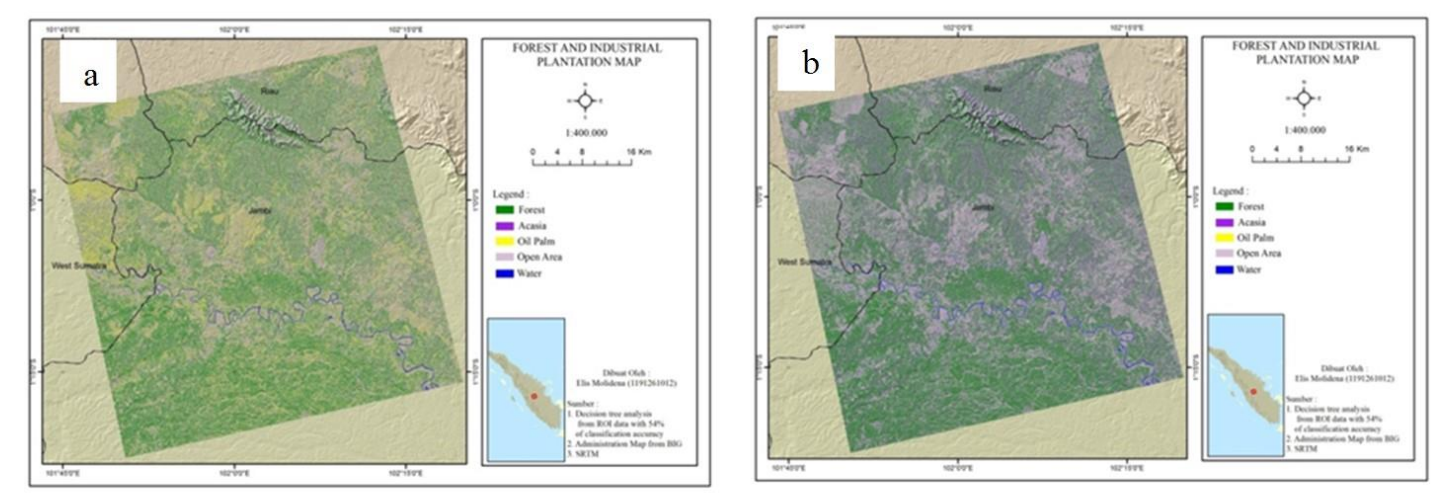

Figure 7. Forest and Industrian Plantation Map (a) from ground truth data (b) from ROI data
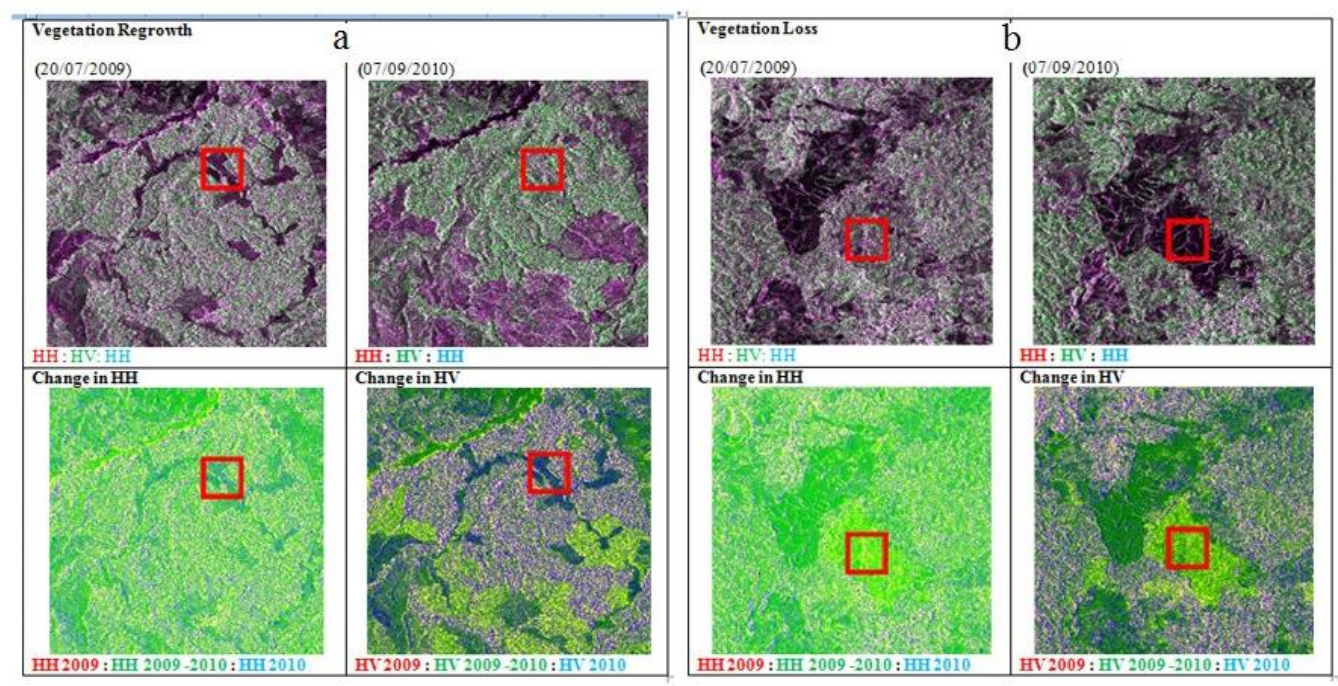

Figure 8. Vegetation loss and vegetation regrowth detected

\subsection{Change Detection}

Change detection can be easily visual detected by makes color composite from PALSAR image from different times, with combination image 2009 red, 2009 - 2010 green, 2010 blue. Comparison pixel-by-pixel data showed us the changes of environmental. We can detect visually vegetation loss, re-growth, and flood or not changes area from those false colors composite. 
Vegetation loss in false color composite showed yellow color, When 2009 image of PALSAR put in red band and 2009 image of PALSAR minus 2010 image of PALSAR put in green band, it can detected loss of vegetation, the combination red color and green color will can give yellow color in the object, and also see comparison the difference between image of PALSAR 2009 and image of PALSAR 2010, inside the red box in image of PALSAR 2009 showed some vegetation but in 2010 image of PALSAR all the vegetation was gone by clear cutting activities.

Vegetation re-growth in false color composite in blue color, When 2009 image of PALSAR put in red band and 2010 image of PALSAR put in blue band, it can detected vegetation re-growth, when there's no vegetation in 2009 image of PALSAR, but vegetation appears in 2010 image of PALSAR so the color of object in image dominate by magenta color, and we cal also see comparison the difference between 2009 image of PALSAR and 2010 image of PALSAR, in 2009 image of PALSAR showed some open area but in 2010 image of PALSAR shows all the open area become vegetation area.

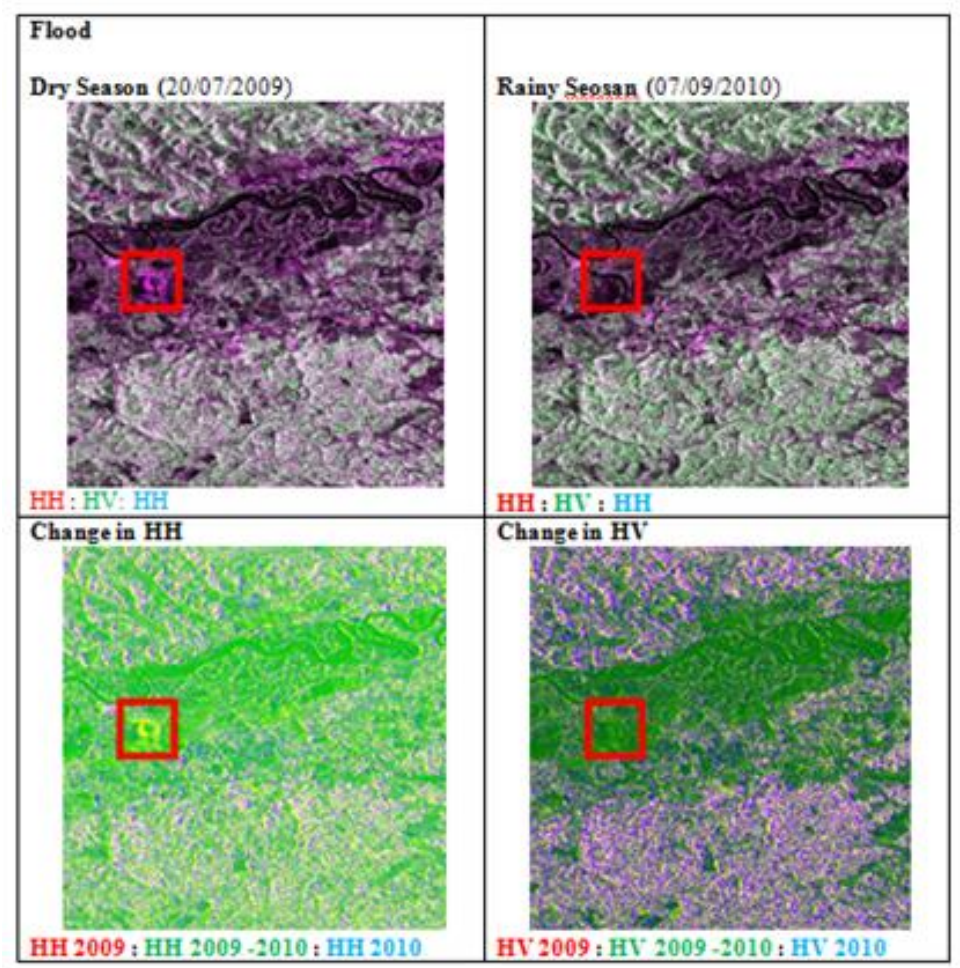

Figure 9. Flood detected

Flood shows by seasonal change when in dry season object will appears like open area or it can be other object, but when rainy season it becomes water on the surface, because of water emitted low backscatter into the satellite the image become will appears dark, as showed in red box, flood can easy detected visually in $\mathrm{HH}$ false color composite than in HV false color composite

\section{Discussion}

ALOS PALSAR L band data were used for classification of five categories forest, acasia, oil palm, open area and water. L band was representing good classification of vegetation because of the L-band has good penetration in vegetation area, with an overall classification accuracy of $72.2 \%$ land cover classification, such as forest, plantation (Li et al., 2012). This research tested the capability of PALSAR fine beam dual (FBD) horizontal/horizontal (HH) and horizontal/vertical (HV) polarization data for classification. The backscattering intensity values were used for defining different land use types.

Plantation ages, water content of vegetation, size of trunks, branches and leaves can effected the backscattering intensity value (Imhoff, 1995), Forest, acacia and mature oil palm shows high statistic value either in $\mathrm{HH}$ and $\mathrm{HV}$ polarization because of crown and 
branch, vegetation in natural forest have many branch and crown like acacia, and size of mature oil palm leave makes backscattering value of oil palm similar to forest and acasia. Vegetation area appears light grey in the image.

Open area appears dark grey with low backscattering intensity value, because of some of the incident radar energy is able to penetrate into the soil surface, and makes less backscattering intensity, surface scattering in rough surface happen in open area. In the classification image results, some of open area define as a oil palm, the reason is oil palm in that area is a young oil palm because of young oil palm plantation only have a small crown layer and ground layer. The satellite transmitted signal to oil palm and send backscattering to the satellite from the ground layer and crown layer, backscattering from ground layer is dominant than crown layer, it makes value of oil palm similar to open area.

Water area showed very dark with the lowest of backscattering intensity value, radar specularly reflected off the water surface. Based on Imhoff (1995), when the satellite transmitted the the signal to the water, only a little intensity of the backscattering are send back to the satellite.

Polarization is characteristic to show different conditions of each object reflectance, depending on the direction of reflectance wave, multi polarimatric can be used for land cover or land use classification. The result shows that $\mathrm{HH}$ polarization has more high value than $\mathrm{HV}$ polarization however, $\mathrm{HV}$ polarization has better contrast then $\mathrm{HH}$ polarization to separate vegetation, open area and water because of $\mathrm{HH}$ polarization cut the horizontal object like trees and HV didn't cut object, so in HV polarization vegetation can be separated from open area and water.

There are some miss classifications which was showed due to some noise, the classification method needed to improve some filtering methodology. The accuration of classification showed $62 \%$ based on ground truth data and based on image data $(54 \%)$ because of sample area of ground truth image are points, the point is the exactly pixel of object and the image data utilizated classification training area by polygon used, it's possibility that in the inside of polygon there are mixed pixel and some of noise appears, the accuracy decrease of result because of noise. The low accuracy $(62 \%)$ occurred from defining the rules of decision tree classification.

More than one radar images of the same area acquired at different time can be combined to give Multi temporal color composite images analysis and it can be used for change detection over period of image acquisition. This research also tried to combine two different period time's images, one images of 2009 on red band, 2009-2010 on green band and 2010 on blue band. Color composite combination showed as a key to interpret changes. Decrease of signal means of regrowth, the combination color between blue (image of PALSAR 2010) and green (image of PALSAR 2009 minus image of PALSAR 2010) will produce a cyan color. Increase of signal means of vegetation loss, the combination color between red (image of PALSAR 2009) and green (image of PALSAR 2009 minus image of PALSAR 2010) will produce a yellow color. No change of signal means of no changes appears the combination color between red (image of PALSAR 2009) and blue (image of PALSAR 2010) will produce magenta color. This technique can showed changes either natural changes and man made changes, natural changes like vegetation regrowth, flood and man made changes like clear cutting.

\section{Conclusions}

This result could be concluded as following:

1. ALOS PALSAR L band data can be used for forest and industrial plantation mapping with backscattering value of forest $2,98 \mathrm{~dB}$ in $\mathrm{HH}$ and $\quad-2,72 \mathrm{~dB}$ in $\mathrm{HV}$, acasia 1,68 $\mathrm{dB}$ in $\mathrm{HH}$ and $-4,07 \mathrm{~dB}$ in $\mathrm{HV}$, oil palm 2,06 dB in $\mathrm{HH}$ and $-3,35 \mathrm{~dB}$ in $\mathrm{HV}$, open area $2,62 \mathrm{~dB}$ in $\mathrm{HH}$ and $-13,46 \mathrm{~dB}$ in $\mathrm{HV}$, water $-12,73 \mathrm{~dB}$ in $\mathrm{HH}$ and $-19,15 \mathrm{~dB}$ in $\mathrm{HV}$, and have classification result $62 \%$ accuracy compared with ground truth data base.

2. Multi temporal analysis was employed for visual interpretation to detect the change by ALOS PALSAR image and show the possibility for detecting loss of vegetation, vegetation regrowth or seasonal changes of environment around the location of research study like flood 


\section{References}

Bormudoi, A., Hazarika, M. K., Schumann, R., Samarakoon, L. (2010). A Comparision of Backscatter Coefficients of ALOS PALSAR FBD Product in Diffrent Ground Conditions. In Proceedings $31^{\text {st }}$ Asian Conference on Remote Sensing. Hanoi, Vietnam, 1-5 November 2010 (pp. 436-441)

Butler, R. A. (2011). Indonesia Borneo and Sumatra Lose 9\% of forest cover in 8 years. [online]. Mongabay News \& Inspiration from Nature's Frontline. (https://news.mongabay.com/2011/02/indonesian-borneo-and-sumatra-lose-9-of-forest-coverin-8-years/), [diakses: 4 Maret 2019].

Feilong, L., Zengyuan, L., Erxue, C., Qinmin, W. (2008). Forest Mapping With Multi-temporal Dual Polarization ALOS PALSAR Data. In International Conference on Earth Observation Data Processing and Analysis. Wuhan, China, 29 Desember 2008 (pp.1-11).

Campbell, J. B. (1987). Introduction to Remote Sensing. New York, USA: The Guilford Press.

Colwell, J. E., \& Weber, F. P. (1981). Forest change detection. In International Symposium on Remote Sensing of Environment, 15 th, Ann Arbor, MI (pp. 839-852).

Imhoff, M. L. (1995). Theoretical analysis of the effect of forest structure on synthetic aperture radar backscatter and the remote sensing of biomass. IEEE Transactions on Geoscience and Remote Sensing, 33, 341-352.

Li, G., Lu, D., Moran, E., Dutra, L., \& Batistella, M. (2012). A comparative analysis of ALOS PALSAR L-band and RADARSAT-2 C-band data for land-cover classification in a tropical moist region. ISPRS Journal of Photogrammetry and Remote Sensing, 70, 26-38.

Luckiesh, M. (1921). Color and its applications. New York, USA: D. Van Nostrand Company.

Rakwatin, P., Longépé, N., Isoguchi, O., Shimada, M., Uryu, Y., \& Takeuchi, W. (2012). Using multiscale texture information from ALOS PALSAR to map tropical forest. International journal of remote sensing, $\mathbf{3 3}(24), 7727-7746$.

Rosenqvist, A., Shimada, M., Ito, N., \& Watanabe, M. (2007). ALOS PALSAR: A pathfinder mission for global-scale monitoring of the environment. IEEE Transactions on Geoscience and Remote Sensing, 45(11), 3307-3316.

Shimada, M., Isoguchi, O., Tadono, T., \& Isono, K. (2009). PALSAR radiometric and geometric calibration. IEEE Transactions on Geoscience and Remote Sensing, 47(12), 3915-3932.

Uryu, Y., Mott, C., Foead, N., Yulianto, K., Budiman, A., Setiabudi, Takakai, F., Nursamsu, Sunarto, Purastuti, E., Fadhli, N., Hutajulu, C. M. B., Jeanicke, J., Hatano, R., Siegert, F., Stuwe, M. (2008). Deforestation Forest Degradation Biodiversity Loss and $\mathrm{CO}_{2}$ Emition in Riau, Sumatra, Indonesia. Technical Report. Jakarta, Indonesia: WWF Indonesia.

(C) 2018 by the authors; licensee Udayana University, Indonesia. This article is an open access article distributed under the terms and conditions of the Creative Commons Attribution (CC-BY) license (http://creativecommons.org/licenses/by/4.0/). 